\title{
Next Pregnancy and Nutritional Challenges
}

\author{
Shadia Mohamed ${ }^{1}$, Rawan Abdulaziz Alshaghdly ${ }^{2}$ \\ ${ }^{1}$ University of Bahri \\ ${ }^{2}$ University of Hail
}

\begin{abstract}
Every pregnancy has its risks. When certain medical conditions arise before or during pregnancy, more careful monitoring is needed. Objectives: The purpose of this study to determined the prevalence of nutritional challenges in the next pregnancy. According to the lack of information available on consequence of next pregnancy on the mother health and the outcome of the pregnancy at Hail/KSA, the present study was designed to collect information from woman who experience with next pregnancy. Material and Method: 105 questionnaires were submitted to collected information at University of Hail/ college of Applied Science. 105 female experience next pregnancy, were interview to collect information related to their socioeconomic status, age, dietary intake, problems facing women after the next pregnancy. In addition, self reported weight and height was collected. Result: The general characteristics of the population, educated to university level and work $56.5 \%$, with high economic status 60.2 . There are nutrition challenges $66 \%$. With high BMI 40\%, which indicate over weight between the studied groups, there is significant relationship between mean age of study group and Body Mass Index (p-value 0.027). There is significant relationship between nutritional challenges in pregnancy and number of deliveries (p-value 0.0274). There is significant relationship between nutritional challenges in pregnancy and occupation (p-value 0.038). Conclusion: There are nutritional challenges facing women at Hail community. Nutrition education should be carry at Hail community to reduce of nutrition challenges facing women during pregnancy.
\end{abstract}

Keyword: pregnancy, nutrition, challenges, BMI, health, Delivery, Hail

\section{Introduction}

Approximatelyl0 \% of all pregnancies are considered "high risk," meaning a maternal preexisting complication or a situation that presents in the gestation that puts the fetus at risk for in utero injury or premature delivery and subsequent morbidity (1).

It is often after 4 weeks of gestation that a woman learns she is pregnant, which corresponds to 2 weeks after a missed menses. Pregnancy is counted from the first day of the last menstrual cycle. Maternal nutritional status has been evaluated primarily for infant birth weight, risk of neural tube defects (NTDs), and fetal alcohol syndrome. Birth weight is highly correlated with infant mortality and morbidity Newborns born small for gestational age (SGA) are at increased risk for long-term health adversity such as hypertension, obesity, glucose intolerance, and cardiovascular disease. Besides a woman's dietary intake, other factors such as air quality and purity of water can contribute adversely to a pregnancy (2).

\subsection{Nutritional Requirements}

Fetal growth and pregnancy demand additional nutrients, and these requirements are defined in the new dietary reference intakes (DRIs), which include adequate intakes (AIs) and RDA (3)

\subsection{Energy}

Additional energy is required during pregnancy to support the metabolic demands of pregnancy and fetal grou.th. Metabolism increases by 15\% in pregnancy. The 2002 DRIs for energy for the pregnant female are the same as for the non-pregnant female in the first trimester but then increase an additional 340 to $360 \mathrm{kcal} /$ day during the second trimester and another $112 \mathrm{kcal} /$ day in the third trimester. (4)
If maternal weight gain is within the desirable limits, the range of acceptable energy intakes varies widely, given individual differences in energy output and basal metabolic rate.

Energy expended in voluntary physical activity is the largest variable in overall energy expenditure' Physical activity increases energy expenditure proportional to body weight. However, most pregnant women compensate to increased weight gain by slowing work place; thus total daily energy expenditure may not be substantially greater than before pregnancy. Excessive exercise, combined with inadequate energy intake, may lead to suboptimal maternal weight gain and poor fetal growth; therefore a pregnant woman should always discuss exercise with her primary health practitioner. (5)

Acute insults at early gestation, resulting in rapid drop in oxygen delivery to the fetal brain at a time when neurogenesis and neural migration are at their peak, can result in the death of neurons, including Purkinje cells in the cerebellum pyramidal cells in the hippocampus and cortical neurons, and a slowing of neural mitigation, at least in the hippocampus. (6)

Exercising during pregnancy at high altitudes may compromise fetal oxygen delivery. Resting uterine blood flow is lower in residents residue at $3100 \mathrm{~m}$ than at $1600 \mathrm{~m}$. and blood flow is likely to decrease further during exercise in proportion to the intensity and duration. A more conservative stance regarding exercise at elevations over 1600 m during pregnancy may need consideration. (7).

\subsection{Protein}

There is an additional protein requirement for a pregnant woman to support the synthesis of maternal and fetal tissues. 


\section{International Journal of Science and Research (IJSR) \\ ISSN (Online): 2319-7064 \\ Index Copernicus Value (2013): 6.14 | Impact Factor (2014): 5.611}

Protein requirement increases throughout gestation and is maximum during the third trimester. The current RDA of $0.66 \mathrm{~g} / \mathrm{kg} /$ day of protein for pregnant women are the same as that for the non-pregnant women in the first half of pregnancy and increases for the second half to $7 \mathrm{l}$ g/day.

Protein deficiency during pregnancy has adverse consequences, but limited intakes of protein and energy usually occur together, making it difficult to separate the effects of energy deficiency from those of protein deficiency. Providing extra energy to a pregnant woman influences pregnancy outcome equal to that of providing both energy and protein. Thus it appears that an energy deficit rather than a protein deficit determines an unfavorable pregnancy outcome.( 8).

\subsection{Carbohydrates}

DRIs for carbohydrates in pregnancy are presented. The estimated average requirement (EAR) is $135 \mathrm{~g} /$ day, and the $\mathrm{AI}$ is $175 \mathrm{~g}$ /day (4). This 135 to $175 \mathrm{~g} /$ day is the recommended amount to provide enough calories in the diet to prevent ketosis and maintain appropriate blood glucose during pregnancy. This 175 grams translates to 700 calories and is $35 \%$ of an average2000 calorie/day regime. Careful choices are needed to include all the nutrients for pregnancy in the daily diet.

Daily consumption of whole-grain, breads and cereals, leaf green and yellow vegetables, and fresh and dried fruits should be encouraged to provide additional minerals, vitamins, and fiber. The DRI for fiber during pregnancy is $28 \mathrm{~g} /$ day Careful attention to the selection of foods that are also good sources of iron and folic acid is important. (9)

\subsection{Lipids}

There is no DRI for lipids during pregnancy. The amount of fat in the diet should depend on energy requirements for proper weight gain. However for the first time there is a recommendation (an AI of $13 \mathrm{~g} /$ day) for the amount of n-6 polyunsaturated fatty acids (linoleic acid) and an AI of 1.4 $\mathrm{g}$ /day for the amount of n-3 polyunsaturated fatty acids in the diet.(9)

\subsection{Vitamins}

Certain vitamins have particular significance for optimal pregnancy outcome. In some instances the provision of these specific vitamins may be met through diet, and for others a vitamin-mineral supplement is necessary. Periconceptional multivitamin supplementation has been documented to reduce the risk of heart defects in infants by $430 \%$ if started very early in pregnancy (10)

Folic Acid.. Folic acid requirements increase during pregnancy in response to the demands of maternal erythropoiesis and fetal and placental growth and, most important, for the prevention of NTDs. The RDA for folic acid in pregnancy is $600 \mathrm{mcg}$, a $200 \mathrm{mcg}$ increase over that for non-pregnant females. The IOM recommends that 400 mcg of the $600 \mathrm{mcg} /$ day be provided by folate-fortified foods or supplements because it is better absorbed, with 200 mcg from food and beverages. A tolerable upper intake level (UL) is 800 to $1000 \mathrm{mcg} /$ day from fortified foods or supplements. (11) (12).

Folic acid deficiency is marked by a reduced rate of deoryribonucleic acid (DNA) synthesis and mitotic activity in individual cells. Megaloblastic anemia is the latest stage of folate deficiency, and it may not present until the third trimester; however, white cell morphologic and biochemical changes signaling deficienry may precede overt anemia (In experimental animals maternal folate deficiency is associated with an increased incidence of congenital malformations. Malformations can also occur in infants of women using folate antagonist drugs such as the anticonvulsant medications phenytoin (dilantin), carbamazepine, and diphenylhydantoin. Oral contraceptives and some antibiotics (trimethoprim, triamterene, and carbamazepine) may also cause folate insufficiency (13).

\subsection{Common High-Risk Conditions}

\subsubsection{Gestational Diabetes}

Some pregnant women have trouble controlling their blood sugar, often due to gestational diabetes. Blood sugar (glucose) provides energy for the body. The amount of "sugar" in your blood is kept in a normal range by insulin.. Gestational diabetes usually starts in the latter half of the second trimester. This condition requires closer monitoring before and during pregnancy. The closer blood sugar levels are to the normal range, the better the health of both mom and baby. This also reduces the possibility of giving birth to a large baby - which can be a problem with vaginal delivery.(14)

\subsubsection{Pre-eclampsia}

Pre-eclampsia can develop during the second half of pregnancy, most cases usually occur at or near the end of pregnancy or just after birth. Other terms used to describe pre-eclampsia are toxemia, or pregnancy induced hypertension. Pre-eclampsia causes blood vessels to constrict (get smaller) which makes it harder for the mother's blood flow to support the fetus. The only cure is delivery of the baby.(15). Globally 70,000 women and 500,000 babies die every year as a direct result of preeclampsia. For the mother, it can lead to acute problems in the liver, kidneys, brain and the clotting system, and pre-eclampsia is the most important cause of maternal death.

\subsubsection{Vaginal Bleeding Later in Pregnancy}

The placenta is the link to the mother's blood supply; it is important in providing nourishment to the fetus. Problems with the placenta occur in less than $1 \%$ of all pregnancies. In late pregnancy, vaginal bleeding may be a sign that something is wrong with the way the placenta is attached to the lining of the uterus.( (16)

\subsubsection{Fetal Growth Restriction}

Is usually due to placental problems leading to inadequate nutrition of the baby and overall affects 1 in 10 pregnancies. The time interval between one pregnancy and the next may affect the risk of pregnancy complications. Both short and long interpregnancy intervals have been 


\section{International Journal of Science and Research (IJSR) \\ ISSN (Online): 2319-7064}

Index Copernicus Value (2013): 6.14 | Impact Factor (2014): 5.611

associated with adverse outcome, but the bulk of adverse effects have been associated with short intervals (17) Whether the interpregnancy interval is a significant independent biological risk factor for adverse pregnancy events is important because women have some control over the spacing of their pregnancies and thus could potentially reduce their risk of adverse outcomes. Avoidance of short intervals can be achieved through postpartum provision of contraception, but avoidance of long interpregnancy intervals is more problematic since a desired pregnancy may be precluded by sub fertility, availability of a partner, economic issues, or illness (18)

\subsubsection{Anemia \& Pregnancy}

Your body goes through significant changes when you become pregnant. The amount of blood in your body increases by about 20-30 percent, which increases the supply of iron and vitamins that the body needs to make hemoglobin. Hemoglobin is the protein in red blood cells that carries oxygen to other cells in your body.

Many women lack the sufficient amount of iron needed for the second and third trimesters. When your body needs more iron than it has available, you can become anemic.

Mild anemia is normal during pregnancy due to an increase in blood volume. More severe anemia, however, can put your baby at higher risk for anemia later in infancy. In addition, if you are significantly anemic during your first two trimesters, you are at greater risk for having a pre-term delivery or low-birth-weight baby. Being anemic also burdens the mother by increasing the risk of blood loss during labor and making it more difficult to fight infections.(19).

\section{Study objective}

The main objective of this study to determined the prevalence of nutritional challenges in next pregnancy. According to the lack of information available on consequence of the next pregnancy on the mother health and the outcome of the pregnancy at Hail/KSA, the present study was designed to collect information from woman who experience with more than two deliveries.

\section{Materials and Methods}

\subsection{Sample Population}

105 female were interview to collect information at University of Hail/KSA from women who experience next pregnancy

\subsection{Data Collection and study group Interviews}

Women were interviewed by the researcher using the designed questionnaire. The study procedure and goals were explained to women. Designed questionnaire includes information related to socioeconomic status, age, dietary intake, problems facing women after the second delivery In addition; self reported weight and height was collected.

\section{Result \& Discussion}

\subsection{Result}

Table 1: General characteristics of the population

\begin{tabular}{|c|c|c|c|}
\hline Variable & Categories & Frequency & Percentage \\
\hline Educational status & Primary & 5 & 4.7 \\
\cline { 2 - 4 } & Secondary & 23 & 21.3 \\
\cline { 2 - 4 } & University & 19 & 17.6 \\
\cline { 2 - 4 } & Higher & 61 & 56.5 \\
\hline \multirow{7}{*}{ Occupation } & Work & 61 & 56.5 \\
\cline { 2 - 4 } & Not work & 47 & 43.5 \\
\hline Economic status & Low & 5 & 4.6 \\
\cline { 2 - 4 } & Medium & 38 & 35.2 \\
\cline { 2 - 4 } & High & 65 & 60.2 \\
\hline
\end{tabular}

As shown in table 1, the general characteristics of the study group, $56.5 \%$ of the participants study till university level and above, 56.5\% are work, and $60.2 \%$ have high economic status.

Table 2: Health characteristics of the population

\begin{tabular}{|c|c|c|c|}
\hline Variable & Categories & Frequency & Percentage \\
\hline \multirow{4}{*}{$\begin{array}{l}\text { Pregnancy } \\
\text { stage }\end{array}$} & $\begin{array}{c}\text { Less than } 3 \\
\text { months }\end{array}$ & 3 & 2.8 \\
\hline & $3-6$ months & 7 & 6.5 \\
\hline & $\begin{array}{c}\text { More than } 6 \\
\text { months }\end{array}$ & 42 & 38.9 \\
\hline & $\begin{array}{c}\text { Non } \\
\text { pregnant }\end{array}$ & 56 & 51.9 \\
\hline \multirow{2}{*}{$\begin{array}{l}\text { Nutritional } \\
\text { challenges }\end{array}$} & Yes & 66 & 61.1 \\
\hline & No & 42 & 38.9 \\
\hline \multirow{10}{*}{$\begin{array}{l}\text { Type of } \\
\text { disease }\end{array}$} & Anemia & 1 & 0.9 \\
\hline & $\begin{array}{c}\text { Chest } \\
\text { infection }\end{array}$ & 1 & 0.9 \\
\hline & Diabetes & 11 & 9.3 \\
\hline & $\begin{array}{l}\text { Goiter + } \\
\text { Diabetes }\end{array}$ & 1 & 0.9 \\
\hline & Goiter & 1 & 0.9 \\
\hline & Hernia & 1 & 0.9 \\
\hline & $\begin{array}{l}\text { Hormonal } \\
\text { problems }\end{array}$ & 1 & 0.9 \\
\hline & Heartburn & 5 & 4.6 \\
\hline & $\begin{array}{c}\begin{array}{c}\text { Heartburn + } \\
\text { GIT* }\end{array} \\
\end{array}$ & 1 & 0.9 \\
\hline & No disease & 86 & 79.6 \\
\hline \multirow{4}{*}{ BMI } & Underweight & 1 & 0.9 \\
\hline & Normal & 23 & 21.3 \\
\hline & Overweight & 44 & 40.7 \\
\hline & Obese & 40 & 37.1 \\
\hline
\end{tabular}

*Gastro-intestinal tract problem

As shown in table 2. The health characteristics of the study group to determine the physical condition, nutrition problem and the type of disease before pregnancy. $48.1 \%$ are pregnant, $61 . \%$ facing nutritional challenges on their previous pregnancy, $79 \%$ have no type of disease before pregnancy, $40.7 \%$ overweight. 


\section{International Journal of Science and Research (IJSR) \\ ISSN (Online): 2319-7064 \\ Index Copernicus Value (2013): 6.14 | Impact Factor (2014): 5.611}

Table 3: Intake of different food groups during pregnancy

\begin{tabular}{|c|c|c|c|}
\hline Foods & Category & Frequency & Percentage \\
\hline \multirow[t]{3}{*}{ Meat } & No intake & 7 & 6.5 \\
\hline & Intake / day & 65 & 60.2 \\
\hline & Intake / week & 25 & 23.1 \\
\hline \multirow[t]{3}{*}{ Milk } & No intake & 6 & 5.6 \\
\hline & Intake / day & 78 & 72.2 \\
\hline & Intake / week & 14 & 13.0 \\
\hline \multirow[t]{3}{*}{ Fish } & No intake & 20 & 18.5 \\
\hline & Intake / day & 21 & 19.4 \\
\hline & Intake / week & 31 & 28.7 \\
\hline \multirow[t]{3}{*}{ Chicken } & No intake & 9 & 8.3 \\
\hline & Intake / day & 67 & 62.0 \\
\hline & Intake / week & 20 & 18.5 \\
\hline \multirow[t]{3}{*}{ Lentils } & No intake & 27 & 25.0 \\
\hline & Intake / day & 21 & 19.4 \\
\hline & Intake / week & 36 & 33.3 \\
\hline \multirow[t]{3}{*}{ Chips } & No intake & 24 & 22.2 \\
\hline & Intake / day & 34 & 31.5 \\
\hline & Intake / week & 22 & 20.4 \\
\hline \multirow[t]{3}{*}{ Cake/ chocolate } & No intake & 20 & 18.5 \\
\hline & Intake / day & 45 & 41.7 \\
\hline & Intake / week & 22 & 20.4 \\
\hline \multirow[t]{3}{*}{ Green veg.s } & No intake & 6 & 5.6 \\
\hline & Intake / day & 56 & 51.9 \\
\hline & Intake / week & 32 & 29.6 \\
\hline \multirow[t]{3}{*}{ Fruits } & No intake & 8 & 7.4 \\
\hline & Intake / day & 54 & 50.0 \\
\hline & Intake / week & 27 & 24.8 \\
\hline \multirow[t]{3}{*}{ Juices } & No intake & 5 & 4.6 \\
\hline & Intake / day & 64 & 59.3 \\
\hline & Intake / week & 21 & 19.4 \\
\hline
\end{tabular}

Table 3 shows the intake of different food group during pregnancy. The food which are taken by the pregnant women /day includes meat $60 \%$, milk78.0\%, chicken $67 \%$, chocolate $54 \%$, green vegetable $51.9 \%$, fruits $50.0 \%$ juiced $59.3 \%$. Theses indicate there is no problem for the food intake of the study group.

Table 4: Mean age and BMI

\begin{tabular}{|c|c|c|}
\hline BMI & Mean age $\pm S D$ & Number \\
\hline Underweight & $27.0 \pm 0.00$ & 1 \\
\hline Normal & $34.17 \pm 6.4$ & 23 \\
\hline Overweight & $35.2 \pm 8.2$ & 44 \\
\hline obese & $38.7 \pm 7.8$ & 38 \\
\hline & ANOVA F $=3.18 \mathrm{df} 3, \mathrm{P}=0.027^{* *}$ \\
\hline
\end{tabular}

As shown in Table No.4. The mean age + SD and body mass index. There is significant relationship between mean age of study group and Body Mass Index (p-value 0.027). The overweight population is high $44 \%$ of the respondent

Table 5: Correlation of Nutritional challenges in pregnancy and Number of deliveries

\begin{tabular}{|c|c|c|c|}
\hline \multirow{2}{*}{ Number of deliveries } & \multicolumn{3}{|c|}{ Nutritional challenges } \\
\cline { 2 - 4 } & Present & Absent & Total \\
\hline 2 & 22 & 17 & 39 \\
\hline 3 & 11 & 1 & 12 \\
\hline 4 & 15 & 10 & 25 \\
\hline 5 & 11 & 7 & 18 \\
\hline More & 7 & 5 & 12 \\
\hline \multicolumn{4}{|l}{} \\
\hline
\end{tabular}

As shown Table No.5 The correlation of nutritional challenges in pregnancy and number of deliveries. There is significant relationship between nutritional challenges in pregnancy and number of deliveries (p-value 0.0274). The respondent facing nutrition challenges according to the number of deliveries

Table 6: Correlation of Nutritional challenges in pregnancy and working status

\begin{tabular}{|c|c|c|c|}
\hline Nutritional challenges & \multicolumn{3}{|c|}{ Occupation } \\
\cline { 2 - 4 } & Work & Not work & Total \\
\hline Present & 39 & 27 & 66 \\
\hline Absent & 20 & 20 & 40 \\
\hline Total & 59 & 47 & 106 \\
\hline & Mc Nemar test - P $=0.0382^{* *}$ \\
\hline
\end{tabular}

As shown Table No.6 the correlation of nutritional challenges in pregnancy and working status. 66\% of the respondent facing nutrition challenges according to their occupation. There is significant relation between nutrition challenges and work status (p-value 0.038).

\subsection{Discussion}

General characteristics of the population, shows high economic status and overweight. There is significant relationship between mean age of study group and Body Mass Index (p-value 0.027).

Women with an unhealthy weight in a first_pregnancy could be at greater risk for complications in their next pregnancy -even if they're at a good weight, a new study finds. While moms who weigh too much or too little might have uncomplicated pregnancies and deliver healthy babies the first time around, our research shows they are still at increased risk of adverse outcomes during their second pregnancies. That risk may not go away even if they are at a normal weight when they get pregnant again," study senior author Jen Jen Chang, associate professor of epidemiology at Saint Louis University, said in a university news release.

Health characteristics of the population represents the absent of any type of disease before pregnancy. The nutrition challenges facing pregnant women include:- Anemia, chest infection, diabetes, heartburn, goiter and problems in gastrointestinal tract.

There is significant relationship between nutritional challenges in pregnancy and number of deliveries ( $p$-value 0.0274). There is significant relation between nutrition challenges and work status (p-value 0.038).

\section{Conclusion}

This study concluded that there are nutritional challenges facing women during their next pregnancies. A healthy weight is the best way to ensure a healthy pregnancy.

\section{Recommendation}

Health education programs should be conducted at community level at Hail/KSA to highlight the risk factors of nutritional challenges on next pregnancy. 


\section{References}

[1] Erick M: Epigenetics: cutting edge science in Maternal and fetal nutrition. Update of vitamin D, calcium, iron, iodine and omega 3 fatty acids. Presented at the Food, Nutrition, Conference and Exhibition of the American Dietetic Association, St Louis, Mo, October 25, 2005.

[2] www.womenshealthct.com/your-health/pregnancy Access on 2014

[3] Mennes T et al: Impact of ambient air pollution on birth weight in Sydney Australia Occup. Environ. Med 62: $52+, 2005$

[4] Luke B: Nutrition in multiple gestations. Clin Perinato 3l 2:403, 2005.

[5] Institute of Medicine, Food and Nutrition Board,: Dietary reference intakes for energy and the macronutrients, carbohydrate, fiber. fat, and fatty acids, Washington, DC, 2 002, National Academies Press.

[6] Rees S, Inder T: Fetal and neonatal origins of altered brain development. Early Hum Dev. 81:7 53, 2005.

[7] Entin PL, Coffin L: Physiological basis for recommendations regarding exercise during pregnancy at high attitudes, High Ah Med Biol 5:321,2004.

[8] Kathleen Mahan, L; (2008): Kruse's Food and Nutrition Therapy. Nutrition during Pregnancy \& Lactation. International Edition, 12e ISBN: 978-0-8089-2378.

[9] Institute of Medicine, Food and Nutrition Board,: Dietary reference intakes for energy and the macronutrients, carbohydrate, Fiber, fat, and fatty acids. Washington, DC, 2 002, National Academies Press.

[10] BaileyL B, Berry RJ: Folic acid supplementation and the occurrence of congenital heart defects, or facial clefts, multiple births, and miscarriage Am J Clin. Nutr. 8l:1235, 2005 '

[11] Institute of Medicine, Food and Nutrition Board: Dietary reference in takes of thiamin, riboflavin, niacin, vitamin 86, folate, vitamin B12, panothonic acid, biotin and choline, Washington, DC, 1998, National Academies Press.

[12] Eichholzer $M$ et al: Folic acid: a public-health challenge. Lancet 367:1352, 2006.

[13] Scholl TO et al: Maternal glucose concentration influences fetal growth, gestation, and pregnancy complications A, m J Epidemiol . 54:514,2 001.

[14] Solomon C G, Seely E W: Brief Review: hypertension in pregnancy: a manifestation of the insulin resistance syndrome Hypertension 37: 232, 2001.

[15]Reid G, Bocking A: The potential for probiotics to prevent bacterial vaginosis and preterm labor, Am J Obstet@Gnecol189:1202, 2003.

[16] Conde-Agudelo A, Rosas-Bermúdez A, Kafury-Goeta AC. Effects of birth spacing on maternal health: a systematic review. Am J Obstet Gynecol 2007; 196:297.

[17] Gemmill A, Lindberg LD.,Short interpregnancy intervals in the United States. Obstet Gynecol 2013; 122:64

[18] Jen Jen Chang, (2015): Weight at first pregnancy links to complication. American Journal of Obstetrics and Gynecology, Saint Louis University, university news. 2015.

[19] WWW.hematology.org patient/anemia/pregnancy2015

\section{Author Profile}

Shadia Mohamed Idriss Bakheit received the B.Sc., M.Sc., PhD, and degree in Home Science / Nutrition from Ahfad University for women, university of Khartoum-Sudan, 1989, 1997, and 2000, respectively. She worked at Khartoum Teaching Hospital Sudan 1990-1997, University of Juba, College of Community Studies \& Rural Development 1997-2011, University of Bahri-Sudan 2011. University of Hail / KSA, 2011-2014. She worked now, as Associate professor at University of Bahri-Sudan.

Rawan Abdulaziz Alshaghdly B. Sc. University of Hail/KSA2014 